\title{
Development of fluorescent protein-marked strains of Bacillus subtilis
}

Ibragimov A. ${ }^{1,2}$, Baymiev An. ${ }^{1,2}$, Lastochkina O. ${ }^{1,3}$

${ }^{1}$ Institute of Biochemistry and Genetics of the Ufa Federal Research Center of RAS, Ufa, Russia; ${ }^{2}$ Bashkir State University, Ufa, Russia; ${ }^{3}$ Bashkir Research Institute of Agriculture of the Ufa Federal Research Center of RAS, Ufa, Russia

E-mail: waywardprowler@gmail.com

Key message. We obtained constructs pHT01-GFP and pHT43-RFP. Recombinant plasmids were transferred into endophytic Bacillus subtilis (strains 10-4 and 26D).

Keywords: Bacillus subtilis, fluorescent proteins, genetic constructs, bacterial transformation

Endophytic Bacillus subtilis are wild-type beneficial bacteria with antifungal, growth stimulation and anti-stress physiological programs induction activities [2,3]. However, the mechanisms of the formation of symbiotic relationships between plants and endophytic strains of Bacillus subtilis are not completely understood, further research in this branch required. The goal of this research was to obtain the strains of B. subtilis 10-4 and 26D marked with the genes of green and red fluorescent proteins ( $g f p$, $r f p)$. The genes of green fluorescent protein $(g f p)$ and red fluorescent protein $(r f p)$ were amplified and then digested with BamHI and cloned to pHT01 and pHT43 plasmids. Recombinant plasmids were extracted from Escherichia coli and transferred into B. subtilis (strains 10-4 and 26D). Transformants were selected on LB plates containing $25 \mu \mathrm{g} \cdot \mathrm{mL}^{-1}$ chloramphenicol $(\mathrm{Cm})$ [1]. The obtained constructs of strains 10-4 and 26D will allow revealing the nature of the symbiotic relationships between $B$. subtilis strains 10-4, 26D and host-plants and reveal the mechanisms of symbiotic relationships formation between endophytic strains and host-plants, the localization of bacteria in plant tissues, monitoring the bacterial circulation in the plant organism, and pathways of the penetration of the bacteria into the host-plants.

This research was funded by the grant of the President of the Russian Federation (№ MK-643.2019.11).

1) Zhang Z., Ding Z.-T., Shu D., Luo D., Tan H. 2015. Development of an efficient electroporation method for iturin Aproducing Bacillus subtilis ZK. Int. J. Mol. Sci. 16(4):7334-7351. doi: 10.3390/ijms16047334

2) Abd-Allah E.F., Alqarawi A.A., Hashem A., Radhakrishnan R., Al-Huqail A.A., Al-Otibi F.O.N., Malik J.A., Alharbi R.I., Egamberdieva D. 2018. Endophytic bacterium Bacillus subtilis (BERA 71) improves salt tolerance in chickpea plants by regulating the plant defense mechanisms. J. Plant Inter. 13(1):37-44. doi: 10.1080/17429145.2017.1414321

3) Deng Y., Chen H., Li C., Xu J., Qi Q., Xu Y., Zhu Y., Zheng J., Peng D., Ruan L., Sun M. 2019. Endophyte Bacillus subtilis evade plant defense by producing lantibiotic subtilomycin to mask self-produced flagellin. Com. Biol. 2:368. doi: 10.1038/s42003-019-0614-0 